\title{
Application of Atom Probe Tomography to Atomic Layer Deposited Thin Films
}

\author{
A.D. Giddings, T.J. Prosa, T. F. Kelly and D.J. Larson \\ CAMECA Instruments, Inc., 5500 Nobel Drive, Madison, WI 53719, USA
}

Through sequential exposure to precursor gases, atomic layer deposition (ALD) grows ultra-high quality thin films. At each step of the growth process, the precursors react with a surface, depositing a limited quantity of material; layer growth rates can be controlled to lower than $0.01 \mathrm{~nm}$ per cycle. Metal-oxides, -nitrides and -sulfides, as well as pure metals, can be fabricated in this manner. The layers deposited are highly conformal with a uniform thickness which can be specified with an atomic layer precision [1]. Figure 1 shows a TEM image of an ALD-grown $\mathrm{ZnO}$ thin film containing 3 monolayers of $\mathrm{Al}_{2} \mathrm{O}_{3}$. The $\mathrm{ZnO}$ has formed into grains with a diameter of $10-20 \mathrm{~nm}$, comparable to the spacing of the nominal $\mathrm{Al}$ containing layers. Determining the composition and the films and distribution of the Al within the grains is important to understanding the mechanisms of alloy film growth by ALD [2]; the high chemical sensitivity and 3D spatial resolution make APT uniquely suited for this task.

Beyond the necessity for atomic-scale characterization to analyze atomic-scale deposition, it is possible to use ALD to completely coat APT specimens. Figure 2 shows the atom map of a FIB-sharpened Si microtip which has been coated in $30 \mathrm{~nm}$ of $\mathrm{ZnO}$. The isotopic peaks of a number of $\mathrm{ZnO}$ complex ions measured from the coating are shown in the mass-spectrum of Figure 3. The spectrum obtained using a reflectron-equipped instrument is a good quality, with a FWHM of 1191 at the $64 \mathrm{Da}$ peak $\left(\mathrm{Zn}^{+}\right)$. There are a number of motivations for trying to coat APT specimens using ALD prior to measurement.

Firstly, the data-quality of an atom probe measurement depends on having a mass-spectrum with sharp, well-defined peaks. By coating a specimen with a film which enhances heat conductivity it may be possible to improve data quality; c.f. D.J. Larson et al., these proceedings. Figure 4 shows the massspectra of a coated and uncoated SiN sample; in this case a large improvement is not observed. Secondly, it has been found that APT data quality and specimen yield are improved when the laser spot focus is smaller, leading to more localized heating [3]. Layers which are highly uniform and possess dimensions comparable to the optical penetration depth create optically active films which may influence the specimen-laser interaction. Lastly, ALD films can be deposited on porous or granular materials, providing a matrix in which to encapsulate samples in a form compatible with standard APT preparation methods. This opens the possibility for the application of APT to new classes of materials, for example nano-diamonds [4].

To find suitable coatings to explore these properties, practical aspects such as the film adhesion and evaporation field need to be assessed. For example, Figure 5 shows the uneven evaporation of a $\mathrm{ZnO}$ coating from a Si microtip. This work provides an overview of our current research into atom probe measurements of ALD materials.

\section{References:}

[1] S.M. George, Chem. Rev. 110 (2010) p. 111.

[2] J.W. Elam and S.M George, Chem. Mater. 15 (2003) p. 1020.

[3] J.H. Bunton et al., Micros. Microanal. 13 (2007) p. 418.

[4] P.R. Heck et al., Lunar and Planetary Institute Science Conference Abstracts (2012) p. 1790.

[5] The authors thank Sundew Technologies, CO, USA, for the ZnO ALD depositions. 


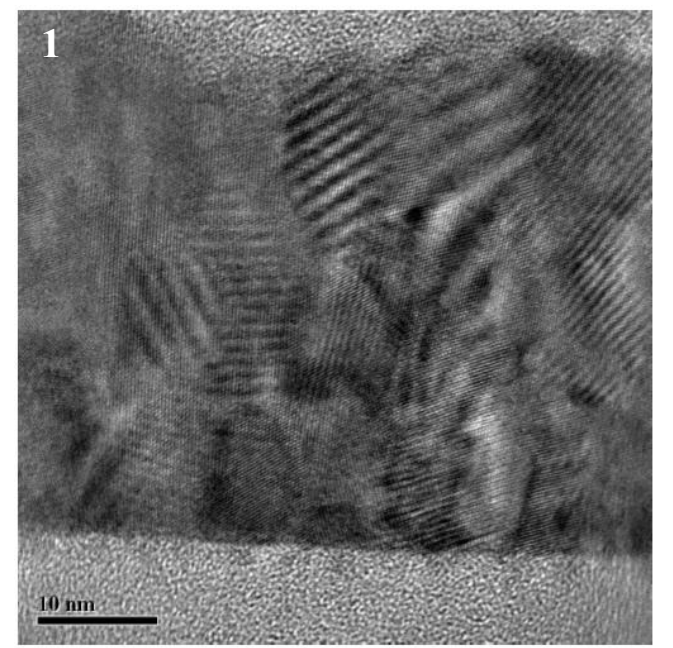

2
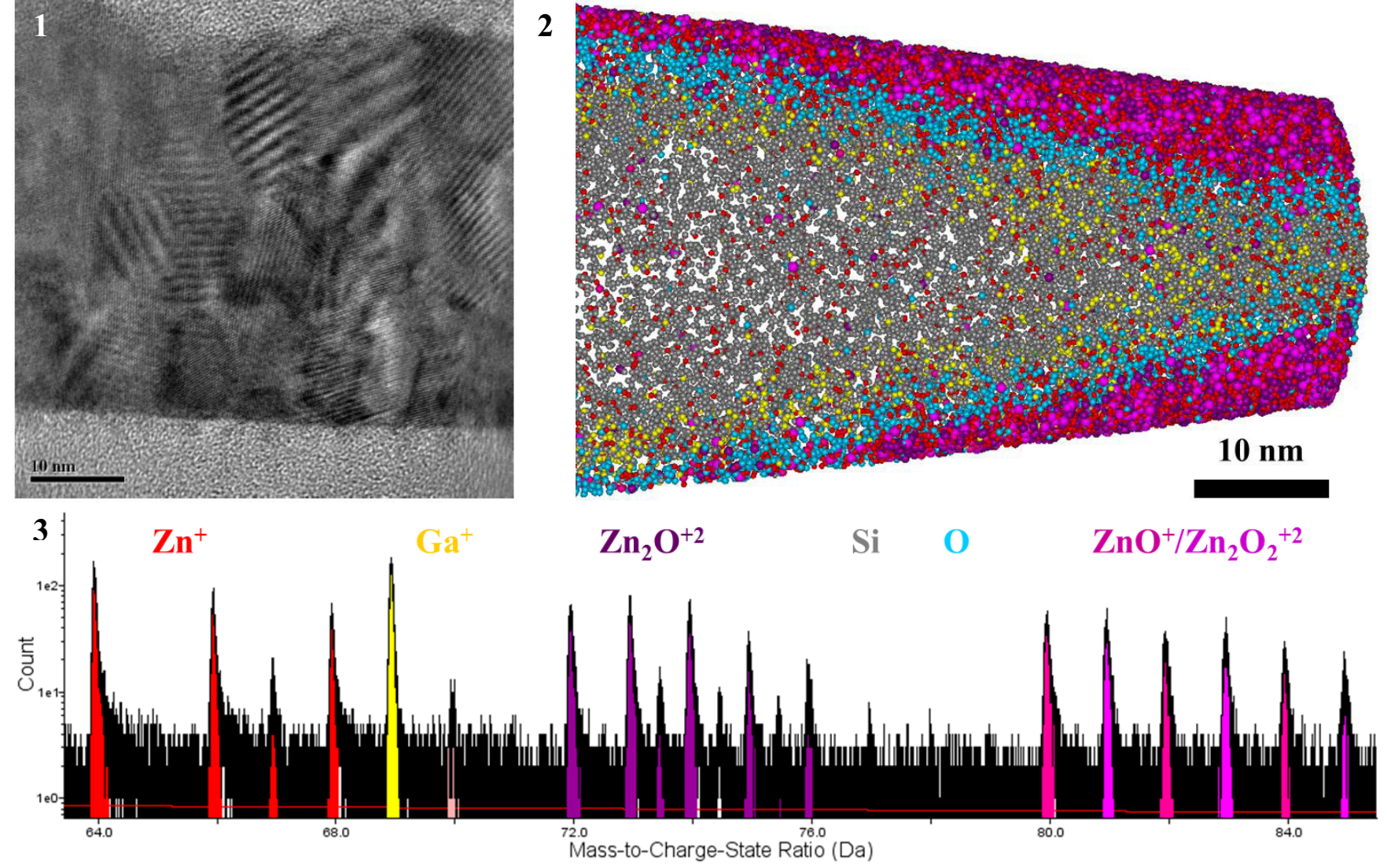

$\mathrm{Zn}_{2} \mathrm{O}^{+2}$

Si $\quad 0$

$\mathrm{ZnO}^{+} / \mathrm{Zn}_{2} \mathrm{O}_{2}^{+2}$
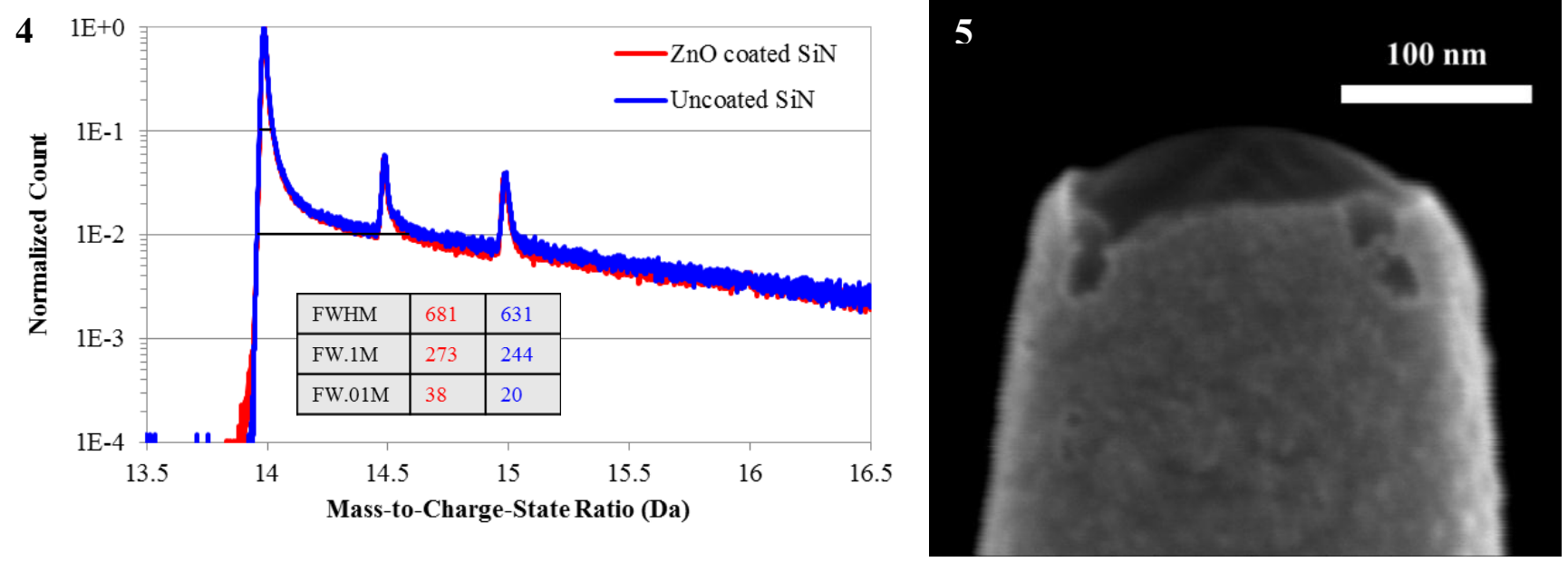

Figure 1. HRTEM image of ALD ZnO containing three A12O3 monolayers (provided by M.A. Verhijen, Eindhoven University of Technology, The Netherlands).

Figure 2. APT atom cloud of a Si microtip coated in $\mathrm{ZnO}$, with the $\mathrm{Si}, \mathrm{Ga}, \mathrm{Zn}, \mathrm{O}$ and $\mathrm{ZnO}$ complexes displayed. The $\mathrm{Ga}$ atoms in the first $5 \mathrm{~nm}$ are a result of damage from FIB milling.

Figure 3. A portion of the mass-spectrum of the tip in Fig. 2 showing the $\mathrm{ZnO}$ complex ions.

Figure 4. Mass-spectra comparing the $\mathrm{Si}^{++}$isotopic peaks for uncoated and $\mathrm{ZnO}$-coated SiN microtips measured using $50 \mathrm{pJ}$ laser pulses and a $90 \mathrm{~mm}$ flight path. The inset table shows the measured massresolving powers.

Figure 5. SEM image of a $\mathrm{ZnO}$-coated microtip post-measurement. The imaging direction is aligned along the laser direction of the measurement. 